Research Letter

\title{
Correction of disorders in tissue perfusion, blood coagulation and fibrinolysis with Orbita apparatus on terahertz waves of cell metabolites
}

\author{
Vyacheslav F. Kirichuk, Alexander A. Tsymbal, Alexey N. Ivanov, Tatyana S. Kiriyazi, Olga N. Antipova, \\ Evgeny V. Andronov, Tatyana S. Velikanova, Vitaly V. Velikanov, Svetlana S. Parshina, Natalia E. Babichenko, \\ Elena V. Ponukalina, Irina V. Smyshlyaeva, Liliana K. Tokaeva, Alexander P. Krenitsyky
}

Saratov State Medical University n.a. V.I. Razumovsky, Saratov, Russia

Received 19 November 2012, Accepted 25 December 2012.

(C) 2012, Kirichuk V.F., Tsymbal A.A., Ivanov A.N., Kiriyazi T.S., Antipova O.N., Andronov E.V., Velikanova T.S., Velikanov V.V., Parshina S.S., Babichenko N.E., Ponukalina E.V., Smyshlyaeva I.V., Tokaeva L.K., Krenitsyky A.P.

(C) 2012, Russian Open Medical Journal

Abstract: This article contains information on principle of operation, technical parameters and possible application of Orbita \{transliteration from Russian\} apparatus for hemodynamic, fibrinolytic and peripheral perfusion disorders treatment. A single exposure to terahertz waves emitted by Orbita apparatus, corresponding to frequencies of molecular absorption and emission spectra of atmospheric oxygen $(129.0 \mathrm{GHz})$, completely cures coagulant and fibrinolytic disorders of animals with acute immobilization stress. A course of treatment with electromagnetic waves corresponding to frequencies of molecular absorption and emission spectra of nitrogen oxide (150.176 - 150.664) leads to normalization of disrupted peripheral tissue perfusion parameters of animal undergoing treatment and stimulates basal and induced output of nitrogen oxide. This leads to decrease in peripheral vascular resistance to microcirculation and increase in blood flow to microvasculature. Experimental data provided in this article serves as a proof of viability of Orbita apparatus for treatment of coagulant, fibrinolytic and tissue perfusion disorders.

Keywords: Orbita apparatus, terahertz waves, nitrogen oxide, atmospheric oxygen, stress, peripheral perfusion, coagulation, fibrinolytic disorders

Cite as Kirichuk VF, Tsymbal AA, Ivanov AN, Kiriyazi TS, Antipova ON, Andronov EV, Velikanova TS, Velikanov VV, Parshina SS, Babichenko NE, Ponukalina EV, Smyshlyaeva IV, Tokaeva LK, Krenitsyky AP. Correction of disorders in tissue perfusion, blood coagulation and fibrinolysis with Orbita apparatus on terahertz waves of cell metabolites. Russian Open Medical Journal 2013; 2: 0102.

Correspondence to Prof. Vyacheslav F. Kirichuk. Address: Department of normal physiology n.a. I.A. Chuevsky, Saratov State Medical University n.a. V.I. Razumovsky, 112, Bolshaya Kazachiya str., Saratov, 410012, Russia. E-mail: normalf@yandex.ru

\section{Introduction}

Nowadays, development of new drug-free methods of hemodynamic disorder treatment is a subject of intense study. One of such methods is application of low-intensive millimeter and submillimeter radiation [1-4].

In recent years, a new branch of information therapy has emerged - terahertz therapy [5]. Terahertz frequency band makes for an interesting research subject because molecular absorption and emission spectra (MAES) of various cell metabolites (NO, CO, active forms of oxygen etc.) belong to this band [6].

Our experimental studies resulted in creation of Orbita \{transliteration from Russian\} apparatus whose principle of operation is based on application of terahertz electromagnetic waves, corresponding to frequencies of molecular absorption and emission spectra of nitrogen oxide $(150.176-150.664 \mathrm{GHz})$ and atmospheric oxygen $(129.0 \mathrm{GHz})$ [7], emitted by special terahertz wave generators created for the first time.

There is evidence of positive effect of the said frequencies energy deposition on rheological properties of blood and platelet functional activity $[8,9]$, coagulant and fibrinolytic activity [10], blood gas and electrolyte concentration [11], lipid peroxidation and antioxidative activity $[12,13]$, functional status of thyroid body [14], primary indices of metabolic status [15], concentration of adrenocorticotropic hormone in blood [16], receptor system of formed blood elements [17], state of vascular endothelium [18] and microcirculation [19].

The aim of this research work is to study the effect of emission produced by Orbita apparatus on peripheral tissue perfusion as well as coagulation and fibrinolytic activities of blood of white rats affected by acute and continuous immobilization stress.

\section{Material and Methods}

A group of 120 male non-pedigree albino rats with average weight of $180-220 \mathrm{~g}$ was chosen as a test subject. All animals were exposed to similar conditions. An acute and continuous immobilization stress caused by a single or daily 3-hour long immobilization performed to test animals for 5 consecutive days was chosen a model system of coagulation and fibrinolytic activities and microcirculation disorders.

The studied animals were divided into 3 groups of 15 animal each: 1st group - control group, 2nd group - comparison group (animals with acute and continuous immobilization stress), 3rd group was comprised of animals exposed to a single terahertz 
radiation (generated by Orbita apparatus) equal to frequency of atmospheric oxygen $(129.0 \mathrm{GHz})$ for 5,15 and 30 minutes (respectively) during acute stress and daily terahertz radiation equal to frequencies of nitrogen oxide (150.176-150.664 GHz) after every 3-hour long immobilization for 5 consecutive days.

Orbita, a terahertz therapy apparatus, contains two radiation heads: one emitting $129 \mathrm{GHz}$ frequency bands and the other 150 $\mathrm{GHz}$ ones. $129 \mathrm{GHz}$ frequency band is one of spectral lines in second zone $(120 \ldots 132 \mathrm{GHz})$ of molecular absorption spectrum of nitrogen oxide (NO). [6]

The apparatus electrical power is supplied by $(220 \pm 22) \mathrm{V}$ power networks with standard frequency of $(50.0 \pm 0.5) \mathrm{Hz}$.

Maximal electrical power consumption of this apparatus does not exceed 15 VA. The apparatus climate class conforms to boreal climate requirements as prescribed by category 4.2 of GOST \{translit\} (Russian State Standard) no. 15150: working temperature range -10 to $35^{\circ} \mathrm{C}$, maximal relative humidity $-80 \%$ at $25^{\circ} \mathrm{C}$; ambient pressure range -84.0 to $106.7 \mathrm{kPa}$ ( 630 to $800 \mathrm{mmHg}$ ).

Primary technical parameters of this apparatus are as follows:

1. Central frequency of generator with KRPG.431111.001-01 head: $150.0 \pm 0.75 \mathrm{GHz}$;

2. Radiation power output: $100 \mu \mathrm{W}$;

3. Available time range for therapeutic treatment duration: 1...99 minutes;

4. Increment of available time range for therapeutic treatment duration: 1 minute;

5. Maximal electrical power consumption: $15 \mathrm{VA}$;

6. Operating mode setup time: no more than 1 minute;

7. Continuous work time: no less than 8 hours;

8. Expected reliability parameters of apparatus operation (at confidence factor $\mathrm{P}=0.8$ ) shall be as follows:

a. mean time to failure: no less than $\mathbf{4 0 0}$ hours;

b. average useful life: no less than 5 years;

c. mean time to recovery: no more than 3 hours.

Terahertz therapy apparatus consists of MES30A-2PIJ regulated medical type power supply unit $(+9 \mathrm{~V})$ with HO5VV-F networks cable, control and display unit, membrane keyboard and extremely-high frequency (EHF) wave emitter. Diagram chart of terahertz therapy apparatus is provided on Figure 1. Control and display unit contains analog signal generator and general purpose control and display element.

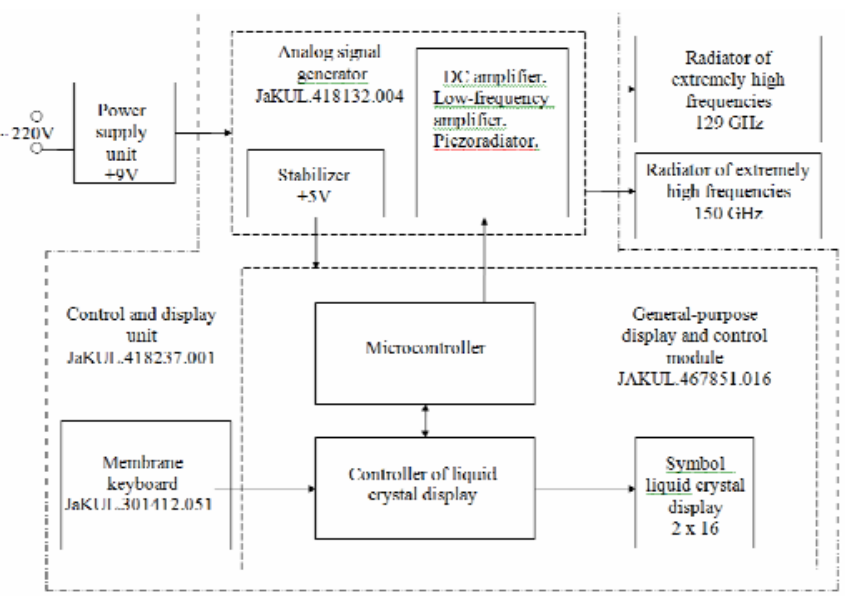

Figure 1. Diagram chart of terahertz therapy apparatus
Analog signal generator of terahertz therapy apparatus performs functions as follows:

- generation of continuous voltage $(+5 \mathrm{~V})$ for general purpose control and display element power supply;

- amplification and stabilization of electric current running through Gunn diode of emitters connected to apparatus;

- connection/disconnection of EHF wave emitter to/from electric power supply network of generator during reception of control signal from microcontroller of general purpose control and display element;

- generation of audible signals during reception of control signal from microcontroller of general purpose control and display element.

JaKUL.467851.016 \{transliteration from Russian\} general purpose control and display element of terahertz therapy apparatus performs functions as follows:

- reception and processing of signals from membrane keyboard;

- control over EHF wave emitters power supply and piezoelectric emitter of analog signal generator;

- provision of information about set operating mode and duration treatment on liquid-crystalline display (LCD).

General purpose control and display element consists of PIC16F876A microcontroller, LCD and keyboard controller and MT16S2D-2VLB symbol (alphanumeric) LCD produced by MJeLT \{transliteration from Russian\} company. Electrical power supply of General purpose control and display element is provided by $\mathrm{L} 7805 \mathrm{CV}$ voltage regulator. The regulator transforms $+9 \mathrm{~V}$ voltage provided by MES30A-2PIJ power supply unit to $+5 \mathrm{~V}$ continuous voltage.

LCD and keyboard controller is built on CE110 microchip. This microchip uses CMDS technology, has a low power consumption rate $(\approx 2 \mathrm{~mA}$ ) and requires only few external discrete components. For example, this microchip does not require connection to crystal oscillator as its clock frequency is generated by a simple RCgenerator. The microchip is connected to electric power supply via CE110 basic connection layout.

PIC16F876A microcontroller produced by MicroChip Company is an eight-bit RISC-based processor. This processor is produced by CMOS FLASH/EEPROM method which provides its low power consumption and high speed performance. Memory size of microcontroller is as follows: FLASH memory $-8 \mathrm{~KB}$, EEPROM memory - 256 Byte (B), data memory - $368 \mathrm{~B}$. Microcontroller can operate in a wide voltage range (from 2.0 to $5.5 \mathrm{~V}$ ). The microcontroller design allows application of crystal oscillator.

PIC16F876A microcontroller of terahertz therapy apparatus performs functions as follows:

- reception and transfer of data and control signals to CE110 LCD and keyboard controller via I2C interface as regulated by a software program recorded into microcontroller;

- transmission of $+5 \mathrm{~V}$ voltage pulse to analog signal generator in order to connect/disconnect emitter to/from power supply as regulated by a software program recorded into microcontroller;

- transmission of $+5 \mathrm{~V}$ voltage pulse to analog signal generator in order to switch 3П-18 piezoelectric emitter on/off and generate audible signals as regulated by a software program recorded into microcontroller. All software is recorded in controller memory. 
Physiology and Pathophysiology

Table 1. Primary characteristics of hemostatic system coagulation measured after exposure of white rats, affected with experimentally induced stress, to terahertz electromagnetic waves equal to frequencies of molecular absorption and emission spectra of atmospheric oxygen (129.0 GHz) for various time

\begin{tabular}{|c|c|c|c|c|c|}
\hline \multirow[t]{2}{*}{ Parameters } & \multirow{2}{*}{$\begin{array}{l}\text { Noninvolved animal } \\
\quad(n=15)\end{array}$} & \multirow{2}{*}{$\begin{array}{l}\text { Animal under } \\
\text { stress } \\
(n=15)\end{array}$} & \multicolumn{3}{|c|}{ Exposure to radiation under stress for the time provided below } \\
\hline & & & $\begin{array}{l}5 \text { minutes } \\
(n=15)\end{array}$ & $\begin{array}{l}15 \text { minutes } \\
(n=15)\end{array}$ & $\begin{array}{l}30 \text { miuntes } \\
(n=15)\end{array}$ \\
\hline \multirow[t]{3}{*}{ APPT, s } & $24.8(21.3,26.3)$ & $19.0(17.9,20.0)$ & $19.9(18.1,21.1)$ & $23.4(21.2,25.5)$ & $25.1(22.8,27.6)$ \\
\hline & & $\mathrm{P}_{1}<0.05$ & $\mathrm{P}_{1}<0.05, \mathrm{P}_{2}>0.05$ & $P_{1}>0.05, P_{2}<0.01$ & $\mathrm{P}_{1}>0.05, \mathrm{P}_{2}<0.05$ \\
\hline & & & & $P_{3}<0.05$ & $P_{3}<0.05, P_{4}>0.05$ \\
\hline \multirow[t]{3}{*}{ Prothrombin time, $\mathrm{s}$} & $19.5(17.3,21.2)$ & $15.0(14.0,18.0)$ & $16.1(15.0,17.8)$ & $17.2(16.2,20.1)$ & $18.8(17.5,21.5)$ \\
\hline & & $P_{1}<0.01$ & $\mathrm{P}_{1}<0.05, \mathrm{P}_{2}>0.05$ & $\mathrm{P}_{1}<0.05, \mathrm{P}_{2}<0.05$ & $P_{1}>0.05, P_{2}<0.01$ \\
\hline & & & & $P_{3}>0.05$ & $\mathrm{P}_{3}<0.05, \mathrm{P}_{4}<0.05$ \\
\hline \multirow{3}{*}{$\begin{array}{l}\text { International normalized } \\
\text { ratio, c.u. }\end{array}$} & $1.22(0.88,1.44)$ & $0.86(0.77,1.11)$ & $0.99(0.80,1.20)$ & $1.01(0.91,1.44)$ & $1.11(1.00,1.35)$ \\
\hline & & $\mathrm{P}_{1}<0.05$ & $\mathrm{P}_{1}<0.05, \mathrm{P}_{2}>0.05$ & $\mathrm{P}_{1}<0.05, \mathrm{P}_{2}<0.01$ & $\mathrm{P}_{1}>0.05, \mathrm{P}_{2}<0.05$ \\
\hline & & & & $P_{3}>0.05$ & $\mathrm{P}_{3}<0.05, \mathrm{P}_{4}<0.01$ \\
\hline \multirow[t]{3}{*}{ Thrombin time, $\mathrm{s}$} & $22.0(19.6,23.5)$ & $15.0(14.2,18.3)$ & $16.4(15.0,18.7)$ & $20.8(19.0,23.3)$ & $21.2(20.0,24.4)$ \\
\hline & & $\mathrm{P}_{1}<0.01$ & $\mathrm{P}_{1}<0.05, \mathrm{P}_{2}>0.05$ & $P_{1}>0.05, P_{2}<0.05$ & $\mathrm{P}_{1}>0.05, \mathrm{P}_{2}<0.05$ \\
\hline & & & & $P_{3}<0.05$ & $\mathrm{P}_{3}<0.05, \mathrm{P}_{4}>0.05$ \\
\hline \multirow{3}{*}{$\begin{array}{l}\text { Fibrinogen concentration, } \\
\mathrm{g} / \mathrm{l}\end{array}$} & $2.0(1.68,2.22)$ & $3.7(1.71,3.75)$ & $3.2(2.0,3.5)$ & $2.9(2.1,3.3)$ & $2.4(1.75,2.5)$ \\
\hline & & $\mathrm{P}_{1}<0.05$ & $\mathrm{P}_{1}<0.05, \mathrm{P}_{2}>0.05$ & $\mathrm{P}_{1}<0.05, \mathrm{P}_{2}<0.05$ & $\mathrm{P}_{1}>0.05, \mathrm{P}_{2}<0.05$ \\
\hline & & & & $P_{3}>0.05$ & $P_{3}<0.05, P_{4}>0.05$ \\
\hline \multirow{3}{*}{$\begin{array}{l}\text { Factor XIII activity in blood } \\
\text { plasma, } \%\end{array}$} & $50.0(45.0,70.0)$ & $75.0(60.0,95.0)$ & $70.0(57.0,80.0)$ & $57.0(44.0,60.1)$ & $54.0(45.2,65.0)$ \\
\hline & & $\mathrm{P}_{1}<0.01$ & $\mathrm{P}_{1}<0.01, \mathrm{P}_{2}>0.05$ & $\mathrm{P}_{1}<0.05, \mathrm{P}_{2}<0.05$ & $\mathrm{P}_{1}>0.05, \mathrm{P}_{2}<0.05$ \\
\hline & & & & $P_{3}<0.05$ & $\mathrm{P}_{3}<0.01, \mathrm{P}_{4}<0.05$ \\
\hline
\end{tabular}

APPT - activated partial thromboplastin time.

Data presented as median, lower and upper quartiles $\left(Q_{1}, Q_{3}\right)$.

Discrepancies with $\mathrm{P}<0.05$ were considered statistically significant. $\mathrm{P}_{1}-$ comparison with uninvolved animal group; $\mathrm{P}_{2}-$ comparison with a group of animal with induced immobilization stress; $P_{3}$ - comparison with a group of animal exposed to radiation under stress for 5 minutes; $P_{4}-$ comparison with a group of animal exposed to radiation under stress for 15 minutes.

The radiation heads consist of brass hull with waveguide channel with $1.6 \times 0.8 \mathrm{~mm}$ section implanted with Gunn diode with in-feed.

Radiation-producing waveguide flange has a thread that can be used to attach a PTFE safety cap transparent for terahertz waves (quenching $-0.3 \pm 0.1 \mathrm{~dB}$ ). Radiation head hull is encased in protective shroud with an identification nameplate containing a six-digit code.

Head power supply is provided by regulated power supply source of control and display unit. Pulse operation of radiation head is provided by switching on impulse power supplied to Gunn diode. In the process of operation the head produces terahertz radiation.

Coagulation and fibrinolytic properties of blood of white affected by acute immobilization stress were studied with a series of tests performed on CGL 2110 "Solar" (Minsk, Belarus) turbidimetric coagulation meter using reagents provided by NPO (research and production association) "RENAM" (Moscow, Russia).

Primary characteristics of hemostatic system coagulation include activated partial thromboplastin time (APPT), prothrombin time, international normalized ratio (INR), fibrinogen concentration, thrombin time and factor XIII activity in blood plasma. Anticoagulant blood potency was studied by determination of activity of natural anticoagulants such as antithrombine-III and protein C contained in blood plasma. Fibrinolytic blood potential was studied with Hageman-dependent and streptokinase-induced euglobulin fibrinolysis by calculating plasminogen reserve index.

Disruption of dermal microvasculature was studied by laser Doppler flowmetry (LDF) on the 6th day since the start of tests with 2 nd version of «LAKK-02» \{transliteration from Russian\} blood flow laser analyzer (produced by NPP (research and production enterprise) "Lazma"”, Russia) and LDF 2.20.0.507WL software program. In order to immobilize tested animal, it was injected (intramuscularly) with a combination of zoletyl (produced by Virbac Sante Animale», France; doze: $0.05 \mathrm{ml} / \mathrm{kg}$ ) and xylazine (produced by "Interchemie», France; doze: $1 \mathrm{ml} / \mathrm{kg}$ ). Sensor of laser blood flow analyzer is attached to the back surface of right foot with an atraumatic plaster. Standard record time was 7 minutes.

Statistical analysis of obtained data was performed with the help of Statistica 6.0 program. Distribution type hypothesis were checked (Shapiro-Wilk test). A majority of obtained data does not comply with Gaussian distribution law, thus, Mann-Whitney U-test was used to compare data.

\section{Results and Discussion}

Exposure of animals affected with immobilization stress to terahertz radiation equal to frequency of atmospheric oxygen $(129.0 \mathrm{GHz})$ for 5 minutes did not cause significant changes of disrupted coagulant and fibrinolytic parameters as evidenced by a lack of statistically significant discrepancies between characteristic parameters of coagulation cascade and fibrinolysis in comparison to non-involved animals. However, there is a statistically significant discrepancy between values of primary characteristics of hemostatic system coagulation and fibrinolytic activity of blood in comparison to non-involved animals (Tables 1 and 2).

It should noted that exposure of animals affected with acute immobilization stress to electromagnetic waves from the aforementioned range for 15 minute lead to partial normalization of characteristic parameters of coagulation cascade and fibrinolysis, i.e. APPT and thrombin time were recovered completely and had no statistically significant discrepancies with the same parameters measured for non-involved animals. However, all other hemostatic parameters had statistically significant discrepancies of those of noninvolved animals (Tables 1 and 2). 
Table 2. Changes of characteristic parameters of anticoagulant and fibrinolytic activities of blood of white rats, affected with experimentally induced stress, after exposure to terahertz electromagnetic waves equal to frequencies of molecular absorption and emission spectra of atmospheric oxygen $(129.0 \mathrm{GHz})$ for various time

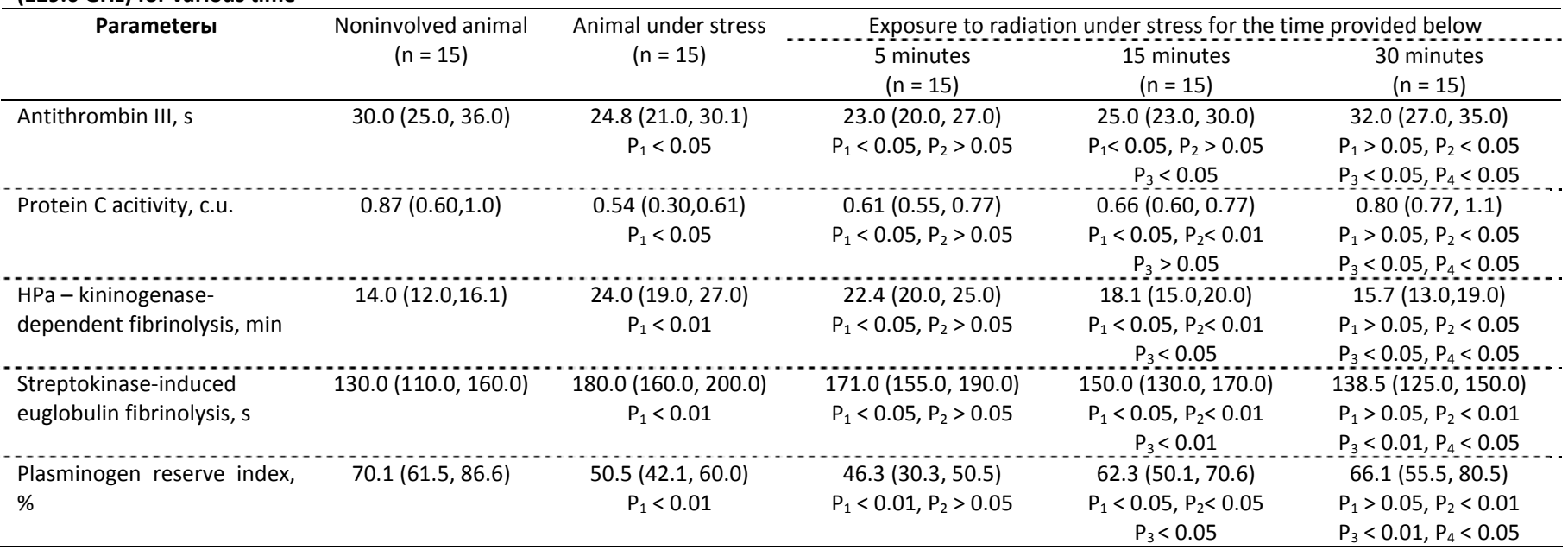

$\mathrm{P}_{1}$ - comparison with uninvolved animal group; $\mathrm{P}_{2}$ - comparison with a group of animal with induced immobilization stress; $\mathrm{P}_{3}-$ comparison with a group of animal exposed to radiation under stress for 5 minutes; $P_{4}$ - comparison with a group of animal exposed to radiation under stress for 15 minutes.

Table 3. Changes of perfusion parameter of animals affected by continuous stress and subjected to a course of treatment with terahertz electromagnetic waves equal to frequencies of molecular absorption and emission spectra of nitrogen oxide $(150.176-150.664 \mathrm{GHz})$

\section{Group}

Parameter
Animals affected with continuous immobilization stress
Animals affected with continuous immobilization stress and subjected to a course of terahertz waves treatment $10.86(9.48,12.47)$ $\mathrm{P}_{1}=0.579, \mathrm{P}_{2}=0.001$ $0.54(0.46,0.67)$ $P_{1}=0.001, P_{2}<0.001$ $4.94(4.64,6.05)$ $P_{1}=0.003, P_{2}=0.032$

\begin{tabular}{|c|c|c|c|}
\hline \multirow[t]{2}{*}{ Mean value of perfusion, $\mathrm{pU}$} & $11.28(9.91,13.34)$ & $7.12(6.39,8.63)$ & $10.86(9.48,12.47)$ \\
\hline & & $P_{1}<0.001$ & $P_{1}=0.579, P_{2}=0.001$ \\
\hline Root mean square deviation of & $1.02(0.75,1.26)$ & $0.29(0.20,0.33)$ & $0.54(0.46,0.67)$ \\
\hline perfusion, pU & & $P_{1}<0.001$ & $P_{1}=0.001, P_{2}<0.001$ \\
\hline \multirow[t]{2}{*}{ Variation coefficient, $\%$} & $8.6(7.17,10.87)$ & $3.49(2.80,5.12)$ & $4.94(4.64,6.05)$ \\
\hline & & $P_{1}<0.001$ & $P_{1}=0.003, P_{2}=0.032$ \\
\hline
\end{tabular}

$\mathrm{P}_{1}$ - comparison with control group; $\mathrm{P}_{2}-$ comparison with a group of animals with continuous stress.

Table 4. Amplitude-frequency characteristics of blood flow oscillations in microvasculature of male rats affected by continuous immobilization stress and subjected to a course of treatment with terahertz electromagnetic waves equal to frequencies of molecular absorption and emission spectra of nitrogen oxide $(150.176-150.664 \mathrm{GHz})$

\begin{tabular}{|c|c|c|c|}
\hline Parameter & Control group & $\begin{array}{l}\text { Animals affected with continuous } \\
\text { immobilization stress }\end{array}$ & $\begin{array}{c}\text { Animals affected with continuous } \\
\text { immobilization stress and subjected } \\
\text { to a course of terahertz waves } \\
\text { treatment }\end{array}$ \\
\hline Maximal amplitude of endothelial & $2.08(1.65,2.81)$ & $0.44(0.30,0.59)$ & $1.20(0.78,1.89)$ \\
\hline oscillations, pU & & $\mathrm{P}_{1}<0.001$ & $P_{1}=0.020, P_{2}<0.001$ \\
\hline Maximal amplitude of vasomotor & $1.33(1.16,1.87)$ & $0.32(0.24,0.38)$ & $0.94(0.48,1.44)$ \\
\hline oscillations, pU & & $P_{1}<0.001$ & $P_{1}=0.035, P_{2}<0.001$ \\
\hline Maximal amplitude of respiratory & $0.34(0.25,0.46)$ & $0.11(0.09,0.20)$ & $0.21(0.15,0.32)$ \\
\hline oscillations, pU & & $P_{1}<0.001$ & $P_{1}=0.059, P_{2}=0.026$ \\
\hline Maximal amplitude of pulse & $0.14(0.11,0.29)$ & $0.06(0.04,0.07)$ & $0.08(0.06,0.11)$ \\
\hline oscillations, pU & & $P_{1}<0.001$ & $P_{1}=0.010, P_{2}=0.022$ \\
\hline
\end{tabular}

$\mathrm{P}_{1}$ - comparison with control group; $\mathrm{P}_{2}-$ comparison with a group of animals with continuous stress.

According to test results, perfusion parameter (M) of male rats, affected by continuous stress and exposed to a series of treatment with Orbita apparatus, recovered completely despite having statistically significantly discrepancies from the same parameter measured for animals in control group (Table 3). A statistically significant increase of root mean square deviation of perfusion parameter and variation coefficient is observed for animals of the aforementioned group compared to animals affected with continuous stress and not exposed to terahertz wave radiation (Table 3 ). It should also be noted that the value of root mean square deviation of perfusion parameter and variation coefficient did not reach the control group value which is an evidence of incomplete recovery of micro blood flow modulation and mechanisms of its regulation.

According to results of amplitude-frequency analysis of LDFcharts, a statistically significant increase of amplitudes of vasomotor and endothelial oscillations was observed for male rats, affected by continuous stress and subjected to a series of exposure to electromagnetic waves equal to frequencies of molecular absorption and emission spectra of nitrogen oxide, compared to animals affected with continuous immobilization 
stress and not exposed to terahertz wave radiation (Table 4). This means that vasodilating activity of endothelium increased (by activation of basal nitrogen oxide production) and peripheral resistance decreased. Amplitudes of respiratory and pulse (cardiac) oscillation also increased (Table 4) which evidences an increment of blood flowing to microvasculature.

\section{Conclusion}

Thus, exposure to radiation emitted by Orbita apparatus is an effective method of non-drug treatment of blood perfusion disorders and normalization of coagulant and fibrinolytic acitivites of blood.

Conflict of interests: none declared.

\section{Reference}

1. Betsky OV, Lebedeva NN. Application of Low-Intensive Millimeter Waves in Biology and Medicine. Biomeditsynksaya radioelectronika (Biomedical Radioelectronics) 2007; (8-9): 6-25. [Article in Russian]

2. Kirichuk VF. Physiological Effects of Extremely High-Frequency and Terahertz Electromagnetic Waves: The Discoveries of Saratov Medical Scientists. Biomeditsynksaya radioelectronika (Biomedical Radioelectronics) 2007; (2-4): 98-126. [Article in Russian]

3. Kirichuk VF. Achievements of Saratov Scientists in Studying the Influence of Extremely High-Frequency and Terahertz Electromagnetic Waves on Humans and Animals. Millimetrovye Volny $v$ Biologii $i$ Meditsyne (Millimeter Waves in Biology and Medicine) 2007; (3): 5-71. [Article in Russian]

4. Kirichuk VF. Results and Perspectives of Experimental Validation of Application of Terahertz Electromagnetic Waves with Frequencies Equal to Frequencies of Molecular Absorption and Emission Spectra (MAES) of Various Cell Metabolites in Clinical Practice. Millimetrovye Volny $v$ Biologii i Meditsyne (Millimeter Waves in Biology and Medicine) 2012; (1): 5-24. [Article in Russian]

5. Kirichuk VF, Golovacheva TV, Parshina SS, et.al. Application of NOtherapy in Clinical Practice. Millimetrovye Volny v Biologii i Meditsyne (Millimeter Waves in Biology and Medicine) 2009; (1-2): 5-21. [Article in Russian]

6. Rothman YS, Gordon JE, Barbe A, Benner D, Bernath PF, Birk M., et al. The HITRAL 2008 Molecular Spectroscopic Database. Journal of Quantitative Spectroscopy and Radioactive Transfer 2009; 110(9-10): 533-572. (doi: 10.1016/j.jpsrt.2009.02.013)

7. Betsky OV, Krenitsky AP, Mayborodin AV, Kirichuk VF. Utility patent: Apparatus for the treatment of electromagnetic waves of extremely high frequency. Russian patent No.50835, 2006.

8. Kirichuk VF, Sukhova CV, Antipova ON. Influence of Exposure to Terahertz Electromagnetic Waves with Frequencies Equal to Absorption and Emission Frequencies of Atmospheric Oxygen on Functional Activity of Platelets of Albino Rats with Immobilization Stress. Biomeditsynksaya radioelectronika (Biomedical Radioelectronics) 2008; (12): 41-48. [Article in Russian]

9. Kirichuk VF, Ivanov AN, Antipova ON, Krenitskii AP, Maiborodin AV, Tupikin VD, Betskii OV. Electromagnetic irradiation of the terahertz diapason at nitric oxide frequencies for correction and prevention of disturbances of platelet functional activity in white rats during longterm stress. Cell and Tissue Biology 2007; 1(4): 357-363. (doi: 10.1134/S1990519X07040086)

10. Kirichuk VF, Tsymbal AA, Krenitsky AP, et al. Application of Terahertz Electromagnetic Waves with $129.0 \mathrm{GHz}$ Frequency of Atmospheric Oxygen for Blood Clotting and Fibrinolytic Disorder Treatment. Biomeditsynksaya radioelectronika (Biomedical Radioelectronics) 2009; (9): 11-16. [Article in Russian]
11. Tsymbal AA, Kirichuk VF. Changes gas and electrolyte structure of blood under influence terahertz radiations on frequencies nitrogen oxide 150,176-150,664 GHz in the conditions of stress. Patol Fiziol Eksp Ter 2011; (1): 49-51. (PMID: 21688667)

12. Kirichuk VF, Tsymbal AA. Effects of terahertz irradiation at nitric oxide frequencies on intensity of lipoperoxidation and antioxidant properties of the blood under stress conditions. Bull Exp Biol Med 2009; 148(2): 200-203. (PMID: 20027328)

13. Kirichuk VF, Tsymbal AA. Use of Terahertz Irradiation at the Frequencies of Nitric Oxide for Correction of the Antioxidant Properties of the Blood and Lipid Peroxidation in Stress. Neuroscience and Behavioral Physiology 2011; 41(5): 495-499. (doi: 10.1007/s11055-011-9443-4)

14. Kirichuk VF, Tsymbal AA. Use of terahertz electromagnetic radiation at nitric oxide frequencies for the correction of thyroid functional state during stress. Vestn Ross Akad Med Nauk (Annals of the Russian Academy of Medical Sciences) 2010; (4): 37-40. (PMID: 20540354)

15. Tsymbal AA, Kirichuk VF, Krenitsky AP. Recovery of Primary Indices of Metabolic Status by Exposure to Terahertz Electromagnetic Waves with Frequencies of Nitrogen Oxide $(150.176-150.64 \mathrm{GHz})$ as a Result of Expirement. Biomeditsynksaya radioelectronika (Biomedical Radioelectronics) 2011; (1): 30-35. [Article in Russian]

16. Tsymbal AA, Kirichuk VF, Antipova ON. Changes of Concentration of Adrenocorticotropic Hormone in Blood of Experimental Animals as a Result of Exposure to Terahertz Electromagnetic Waves with 129.0 $\mathrm{GHz}$ Frequency of Atmospheric Oxygen During Acute and Continuous Stress. Biomeditsynksaya radioelectronika (Biomedical Radioelectronics) 2011; (8): 23-29. [Article in Russian]

17. Kirichuk VF, Ivanov AN, Andronov EV. Influence of Terahertz Electromagnetic Waves with Frequencies of Nitrogen Oxide on Post Stress Disorders of Carbohydrate Component and Activity of Platelet Glycoprotein Receptors. Biomeditsynksaya radioelectronika (Biomedical Radioelectronics) 2010; (5): 39-46. [Article in Russian]

18. Kirichuk VF, Ivanov AN, Kiriyazi TS. Changes in Functional State of Endothelium and Peripheral Perfusion of Albino Rats with Acute Immobilization Stress as a Result of Exposure to Terahertz Electromagnetic Waves with Frequencies of Nitrogen Oxide. Biomeditsynksaya radioelectronika (Biomedical Radioelectronics) 2010; (12): 30-37. [Article in Russian]

19. Kirichuk VF, Ivanov AN, Kirijazi TS. Correction of Microcirculatory Disturbances with Terahertz Electromagnetic Radiation at Nitric Oxide Frequencies in Albino Rats under Conditions of Acute Stress. Bulletin of Experimental Biology and Medicine 2011; 151(3): 288-291. (doi: 10.1007/s10517-011-1311-2)

\section{Authors:}

Vyacheslav F. Kirichuk - MD, D.Sc. Professor, Honored Scientist of Russia, Head of Department of Normal Physiology n.a. I.A. Chuevsky, Saratov State Medical University n.a. V.I. Razumovsky, Saratov, Russia;

Alexander A. Tsymbal - MD, PhD, Associate Professor, Department of Normal Physiology n.a. I.A. Chuevsky, Saratov State Medical University n.a. V.I. Razumovsky, Saratov, Russia;

Alexey N. Ivanov - MD, PhD, Associate Professor, Department of Normal Physiology n.a. I.A. Chuevsky, Saratov State Medical University n.a. V.I. Razumovsky, Saratov, Russia;

Tatyana S. Kiriyazi - PhD, Senior Lecturer, Department of Normal Physiology n.a. I.A. Chuevsky, Saratov State Medical University n.a. V.I. Razumovsky, Saratov, Russia;

Olga N. Antipova - MD, D.Sc., Professor, Department of Normal Physiology n.a. I.A. Chuevsky, Saratov State Medical University n.a. V.I. Razumovsky, Saratov, Russia;

Evgeny V. Andronov - MD, D.Sc., Professor, Department of Normal Physiology n.a. I.A. Chuevsky, Saratov State Medical University n.a. V.I. Razumovsky, Saratov, Russia;

Tatyana S. Velikanova - MD, PhD, Assistant, Department of Normal Physiology n.a. I.A. Chuevsky, Saratov State Medical University n.a. V.I. Razumovsky, Saratov, Russia; 
Vitaly V. Velikanov - MD, Postgraduate, Department of Normal Physiology n.a. I.A. Chuevsky, Saratov State Medical University n.a. V.I. Razumovsky, Saratov, Russia;

Svetlana S. Parshina - MD, D.Sc., Professor, Department of Therapy, Faculty training and retraining of specialits, Saratov State Medical University n.a. V.I. Razumovsky, Saratov, Russia;

Natalia E. Babichenko - MD, PhD, Associate Professor, Department of Normal Physiology n.a. I.A. Chuevsky, Saratov State Medical University n.a. V.I. Razumovsky, Saratov, Russia;

Elena V. Ponukalina - MD, D.Sc., Professor, Department of Normal Physiology n.a. I.A. Chuevsky, Saratov State Medical University n.a. V.I. Razumovsky, Saratov, Russia;

Irina V. Smyshlyaeva - MD, PhD, Associate Professor, Department of Normal Physiology n.a. I.A. Chuevsky, Saratov State Medical University n.a. V.I. Razumovsky, Saratov, Russia;

Liliana K. Tokaeva - MD, D.Sc., Professor, Department of Normal Physiology n.a. I.A. Chuevsky, Saratov State Medical University n.a. V.I. Razumovsky, Saratov, Russia;

Alexander P. Krenitsyky - PhD, General manager of Central Research Institute of the measuring equipment JSC, Saratov, Russia. 